\title{
Erupciones vesiculares secundarias a COVID-19: a propósito de cuatro casos
}

\author{
Vesicular eruptions secondary to COVID-19: apropos of four cases
}

\author{
Jazmín Albavera Giles, ${ }^{*}$ Adriana Miranda Gómez, ${ }^{*}$ \\ María Graciela Guzmán Perera, ${ }^{\ddagger}$ Marcela Saeb Lima ${ }^{\S}$
}

Citar como: Albavera GJ, Miranda GA, Guzmán PMG, Saeb LM. Erupciones vesiculares secundarias a COVID-19: a propósito de cuatro casos. Acta Med Grupo Angeles. 2021; 19 (s1): s37-s41. https://dx.doi.org/10.35366/101026

\section{Resumen}

Dentro del gran espectro de lesiones cutáneas que se han descrito en la enfermedad denominada COVID-19, los exantemas vesiculares ocupan entre el segundo y tercer lugar en frecuencia. Fueron reportados desde las primeras observaciones de Recalcati en el norte de Italia como "Varicela-like", aunque a diferencia de ésta es de naturaleza monomorfa. Pueden presentarse en cualquier parte del cuerpo, el tórax y las extremidades. Es frecuente que se inicien en las manos y se extiendan al tronco en forma secundaria. Se han asociado a dos patrones de presentación, uno localizado y otro diseminado. La dermatosis usualmente acompaña a los síntomas de COVID-19, pero también se ha observado como primer síntoma de la enfermedad. Presentamos dos casos con lesiones aisladas y curso paucisintomático y dos que presentaron lesiones extensas, una con afección pulmonar moderada y la otra con síndrome inflamatorio multisistémico.

Palabras clave: Vesículas, monomorfo, neumonía, síndrome inflamatorio.

\section{CASO 1}

Femenino de 35 años de edad que inicia con vesículas en las caras laterales de la segunda y tercera falange de la mano izquierda, ahora con eccema seco y fisurario del dedo anular. Se obtiene biopsia, donde se observa infiltrado perivascular de los vasos en dermis superior y media. La inmunohistoquímica con antiproteínas de SARS-CoV-2

\section{Abstract}

Within the wide spectrum of skin lesions that have been described in the disease called Covid-19, vesicular rashes rank between second and third in frequency. It has been reported since the first publication of Recalcati in Italy. They can occur anywhere on the body, chest, and extremities. They frequently start in the hands and spread to the trunk secondarily. They have been associated with two presentation patterns, one localized and the other disseminated. The dermatosis is monomorphic and usually accompanies the symptoms of COVID-19 but it has also been observed as the first symptom of the disease. We present two cases with isolated lesions and a pauci-symptomatic course, and two with extensive lesions, one with moderate pulmonary involvement and the other with multisystemic inflammatory syndrome.

Keywords: Vesicles, monomorphic, pneumonia, inflammatory syndrome.
* Dermatóloga del Hospital Ángeles Pedregal.

‡ Dermatóloga del Hospital Ângeles Pedregal, Ex-Presidenta de la Academia Mexicana de Dermatología, Fundación Mexicana para la Dermatología y del Colmexiderma.

$\S$ Dermatóloga y Dermatopatóloga del INCMNSZ, Centro Médico ABC. Hospital Ángeles Lomas, Colmexiderma.

\section{Correspondencia:}

Jazmín Albavera Giles

Correo electrónico: jazzag83@gmail.com

www.medigraphic.com/actamedica

\section{CASO 2}

Paciente femenino de 25 años de edad residente de Playa del Carmen, Quintana Roo, profesionista. Sin antecedentes de importancia para el padecimiento. 
Inicia con aparición de vesículas en el abdomen de contenido hemorrágico, se diseminaron al tórax y después al dorso de las manos.

Acude a consulta, ocho días después presentó PCR para SARS-CoV-2. La paciente permaneció paucisintomática.

Tratamiento: ivermectina/nitazoxanida, fomentos de domeboro y esteroides tópicos. Las lesiones desaparecieron a los cinco días de iniciado el tratamiento (Figura 2).

\section{CASO 3}

Paciente femenino de 61 años de edad, enfermera, sin antecedentes de importancia que acude a consulta por presentar una erupción diseminada a tórax posterior, cuello, axilas y dorso, caracterizada por múltiples vesículas milimétricas hialinas acentuadas sobre una base de piel eritematosa, la cual era pruriginosa (Figura 3).

Tres días posteriores a la erupción vesicular, la paciente inicia con anosmia, ageusia y tos, por lo que se sospecha de enfermedad COVID-19. Se realizó determinación de anticuerpos para SARS-CoV-2 reportando positividad IgM en $3.3 \mathrm{AU} / \mathrm{mL}$ e $\lg \mathrm{G}$ en $12.9 \mathrm{AU} / \mathrm{mL}$.

En la tomografía simple de tórax se reporta neumonía atípica CO-RADS4 con alto nivel de sospecha de COVID-19.

Se realizó biopsia de piel donde se observa en los cortes una vesícula de tipo espongiótica intradérmica, que en su interior muestra infiltrado inflamatorio moderado a expensas de linfocitos, algunos neutrófilos y escasos eosinófilos.
Figura 1:

A) Placas eritematoescamosas en mano que aparecieron después de una erupción vesicular dishidrosiforme.

B) Histología con marcaje para proteína Spike de SARS-CoV-2 positiva.
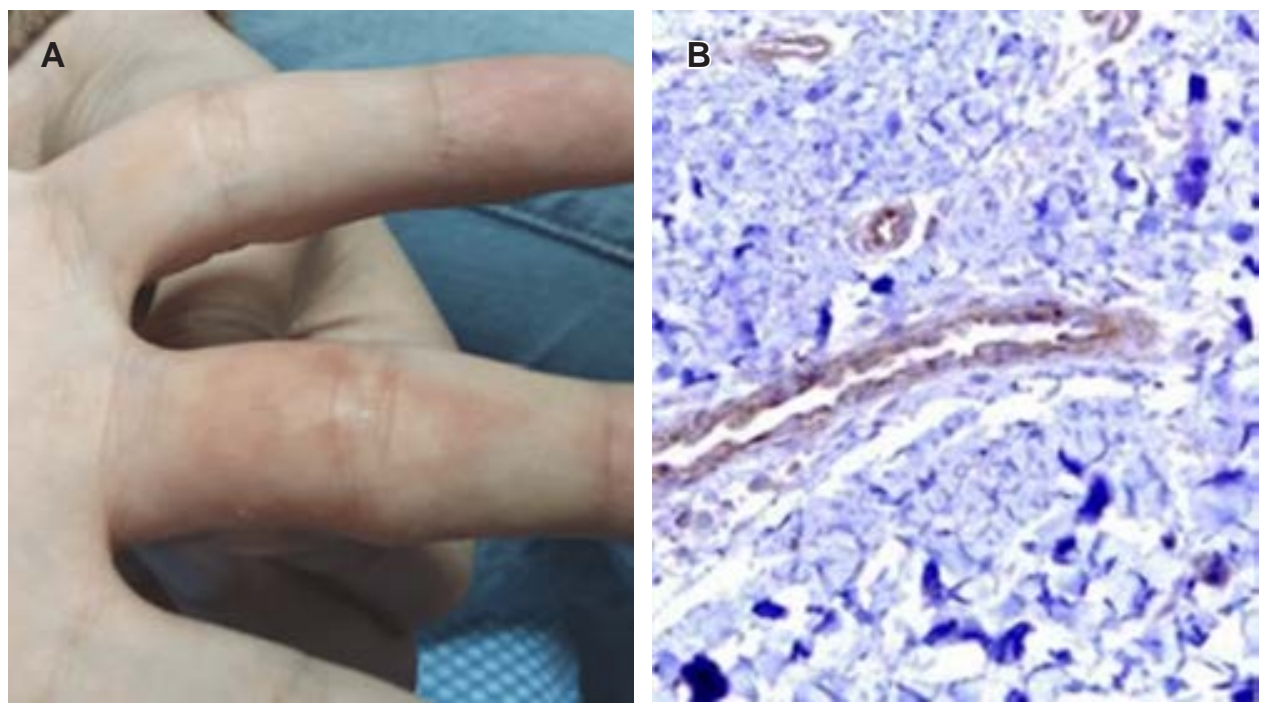
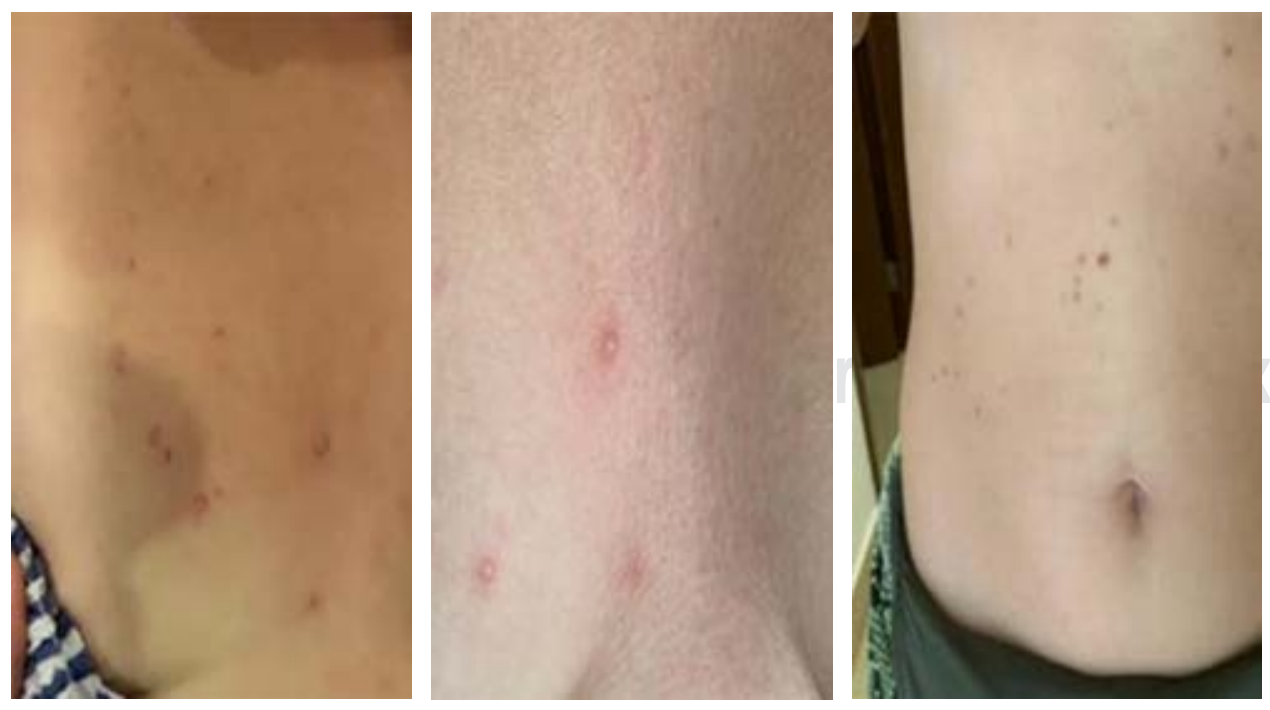

Figura 2:

Exantema vesicular que afecta tórax y abdomen. 


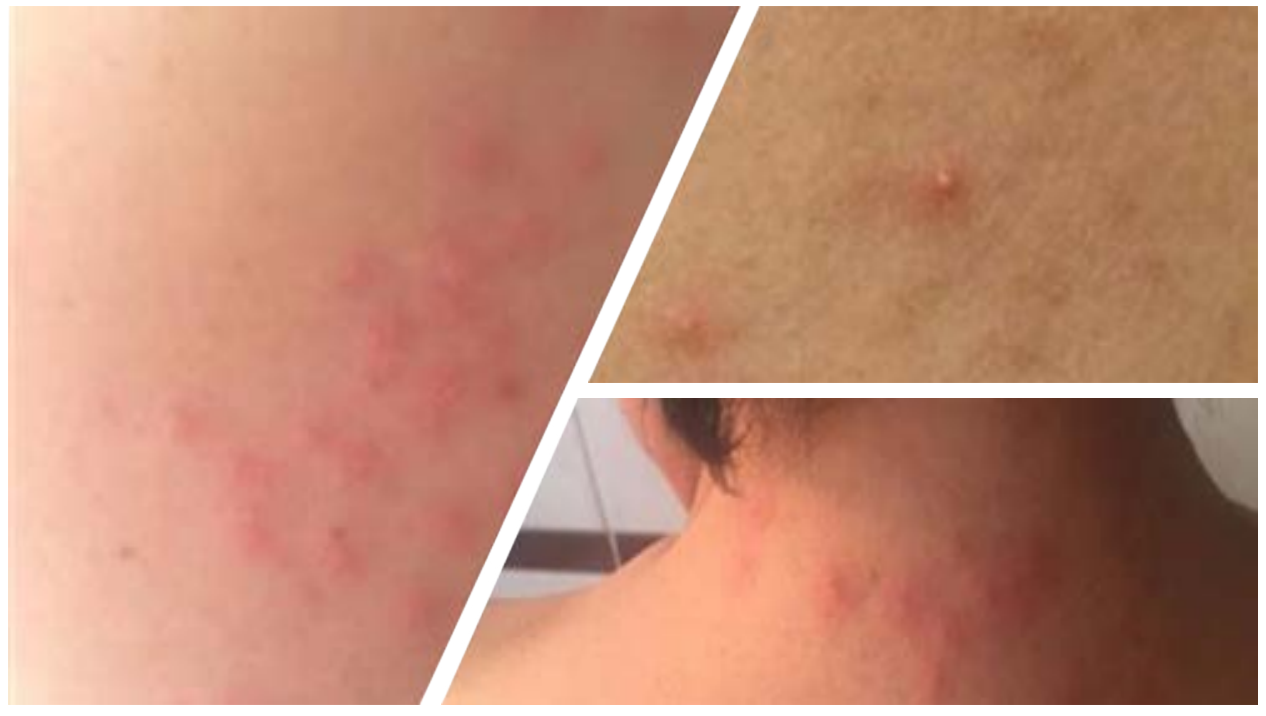

Figura 3:

Exantema vesicular en cuello y brazos.
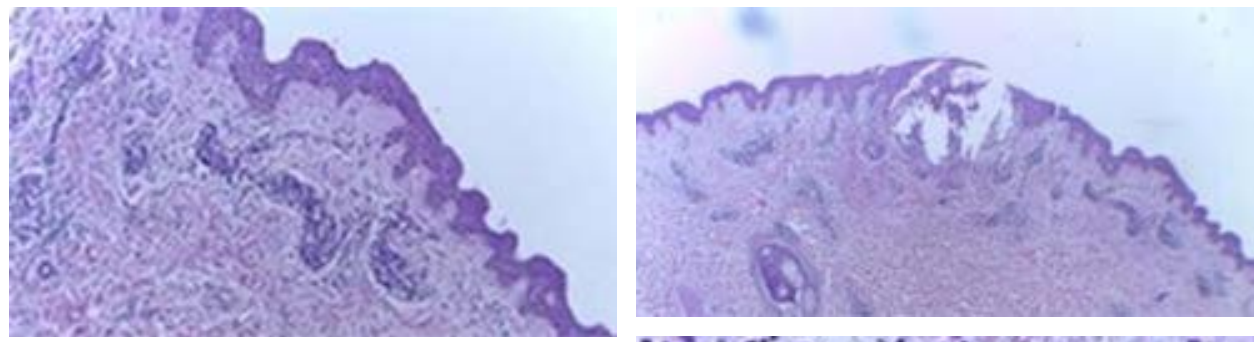

Figura 4:

Biopsia de piel con vesícula intraepidérmica espongiótica, acantolisis discreta, infiltrado inflamatorio perivascular a base de linfocitos. Vasos dilatados y congestionados.
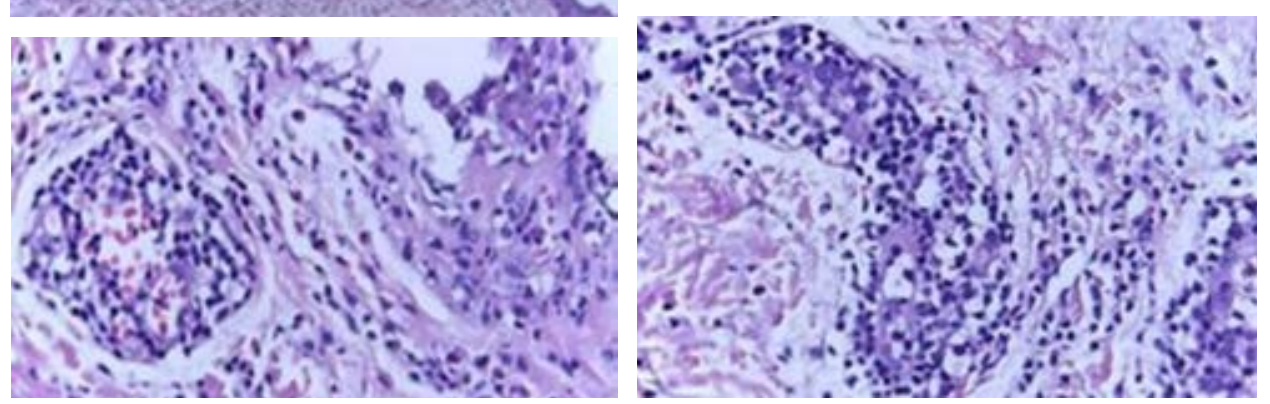

En dermis superficial y media se advierte infiltrado inflamatorio de predominio perivascular a expensas de linfocitos y escasos eosinófilos, además de vasos dilatados y congestionados.

Con reporte de una dermatitis espongiótica aguda y en dermis proceso inflamatorio crónico inespecífico (Figura 4).

Se realizó prueba de anticuerpos de control al mes de la primera determinación reportando elevación de los anticuerpos IgG EN 21.46 AU/mL e IgM $1.28 \mathrm{AU} / \mathrm{mL}$.

La erupción dermatológica fue tratada con esteroides tópicos y lociones secantes, y la infección por SARS-CoV-2 fue tratada por médico internista con hidroxicloroquina $200 \mathrm{mg}$ cada 12 horas por dos semanas, ivermectina 12 mg cada 24 horas por cinco días y azitromicina 1 gramo cada 24 horas por siete días.

Por lo anterior definimos estar frente a una erupción vesicular secundaria a COVID 19, que resolvió satisfactoriamente al resolver el curso de la enfermedad.

\section{$2011 C_{n} 010.11$ CASO 4}

Paciente femenino de 30 años de edad, vecina de la Ciudad de México.

Inicia el 01 de agosto de 2020 con cefalea muy intensa e incapacitante. El 03 de agosto se agrega hipertermia, fatiga y evacuaciones diarreicas. Un día después artralgias, mialgias, eritema conjuntival y edema de los párpados. 
Se realiza prueba para detección de SARS-CoV-2 que resultó negativa.

La paciente continúa con evolución tórpida, aparece odinofagia, anorexia y fatiga al hablar. Su saturación de oxígeno de menos de 90 y taquicardia persistente de 97 y 110 . Se inicia tratamiento con nitazoxanida, vannair y claritromicina. Es internada en el hospital donde se agrega al tratamiento ivermectina, iprikene y dexametasona IV.

El 08 de agosto aparecen vesículas flácidas y traslúcidas que afectaban el dorso de las manos, al romperse dejaban costra violácea que se descamaba (Figura 5).

La tomografía de tórax no mostró focos neumónicos.

El laboratorio mostró fórmula roja normal, leucocitosis de 15,600 con linfopenia y neutrofilia, tromocitopenia de 136,000, enzimas hepáticas y función renal normal. Elevada sedimentación globular, dímero $D$ y ferritina normales. Dos días más tarde elevación de transaminasas y proteína $C$ reactiva de alta sensibilidad elevada.

Persistió con hipoxemia y trastornos del ritmo cardiaco del tipo taquicardia con ciclos de bradicardia. Las pruebas de función tiroidea mostraron presencia de una tiroiditis autoinmune con elevación de anticuerpos antimieloperoxidasa de 1983 y antitiroglobulina de 19.12. Inmunoglobulinas para COVID a las tres semanas negativas.

\section{DISCUSIÓN}

La erupción vesicular descrita asociada a la enfermedad COVID-19 es una erupción vesículo-prurigosa en 68\% de los casos. Puede ser localizada o diseminada, afecta principalmente el tórax, pudiendo extenderse a las extremidades o aparecer sólo en las manos. ${ }^{1}$
La dermatosis tiene un aspecto monomorfo, muestra vesículas sobre base eritematosa que adquieren un aspecto pustuloso en su evolución. Habitualmente se rompen dejando costras. Se presentan en forma temprana o tardía formando costras finas o placas fisuradas. Esta erupción puede recordarnos la enfermedad de Grover cuando aparecen múltiples lesiones y afectan sobre todo el tórax. Se han obtenido pocas biopsias de estos enfermos. El grupo español encabezado por Fernández Nieto ${ }^{2}$ estudió a profundidad los casos que se presentaron en su hospital, encontrando dos tipos de cuadros, el localizado y el diseminado, siendo este último el que se presenta en $75 \%$ de las veces. Este exantema usualmente empieza pocos días después de los signos de COVID 19 a una semana y resuelve sin dejar secuelas. ${ }^{3}$ Suele asociarse con severidad intermedia de la enfermedad COVID-19, con una mortalidad de $10 \%$. Los casos que pudimos observar, dos eran localizados y cursaron con una enfermedad paucisintomatica, los diseminados presentaron síntomas más complejos, neumonía y/o afección multisistémica.

La histopatología revela cambios citopatogénicos típicos de una erupción viral con degeneración reticular de la epidermis, disqueratosis, queratinocitos multinucleados, focos de acantolísis. En los dos casos en los que se hicieron biopsias se encontraron los cambios antes mencionados así como vesículas intraepidérmicas. ${ }^{4}$ En uno de ellos la inmunohistoquímica mostró positividad perivascular a la proteína Spike del virus.

El último y más interesante de nuestros casos se comportó como un síndrome inflamatorio multisistémico (Kawasaki like) muy similar al reportado en la población pediátrica (PIMS: Pediatric inflammatory and multisystemic sindrome). ${ }^{5,6}$ Lo curioso es que en estos casos el paciente rebasa la edad en
Figura 5:

Exantema vesicular que afecta dorso de ambas manos, eritema palmoplantar.
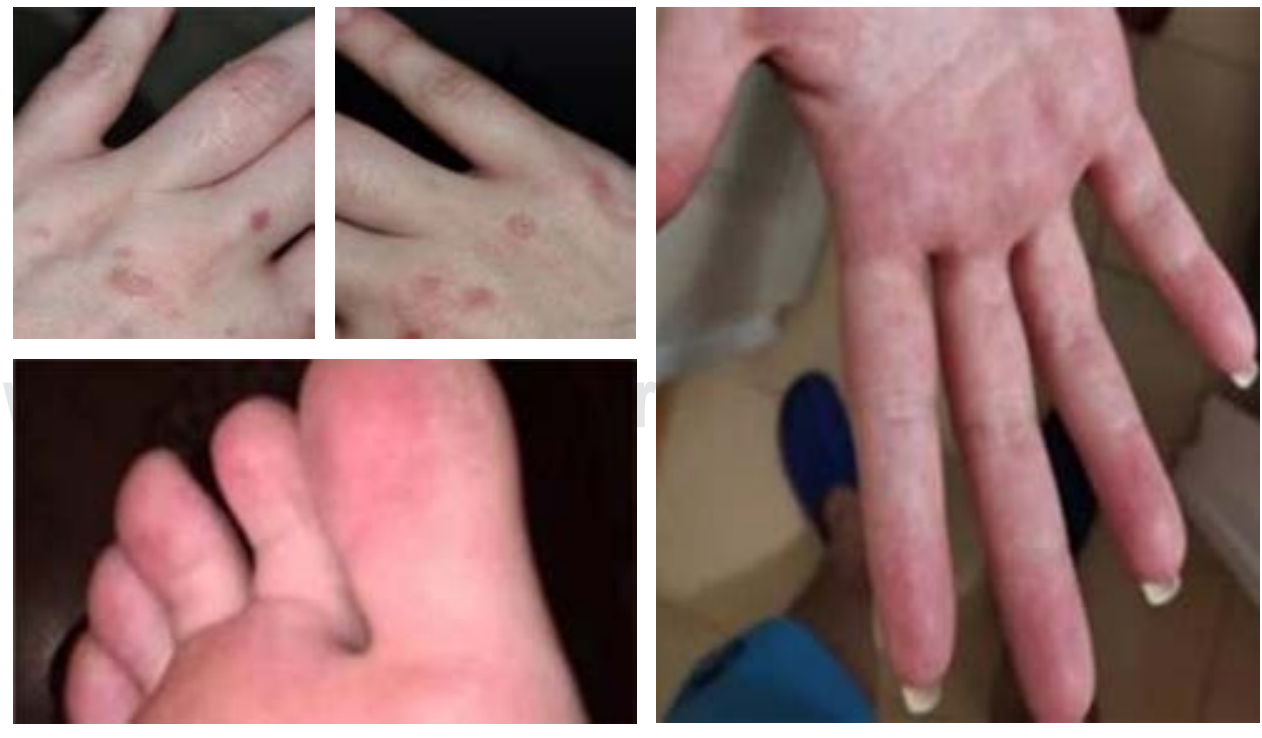
la que se presenta la enfermedad de Kawasaki (menores de cinco años), de hecho, rebasa la edad pediátrica, habiéndose comunicado casos de enfermos mayores de 21 años e incluso una paciente de 31.5

La presentación es con fiebre de difícil control, diarrea, eritema palmoplantar, exantema vesicular, afección cardiaca con trastornos del ritmo, que nos hablan de miocarditis que lleva a trastornos hemodinámicos y choque. Hay elevación de troponinas, dímeros- $D$, ferritina, transaminasas, afecciones hematológicas como leucocitosis con linfopenia, trombocitopenia y alargamiento de los factores de coagulación. ${ }^{5,6}$ También se ha reportado tiroiditis, ${ }^{7}$ que se presentó en nuestra paciente. Cuando las pruebas para aislar el virus son negativas y aún cuando el cuadro clínico sugiera la presencia del virus SARS-CoV-2 e histológicamente la biopsia sea positiva al marcaje inmunohistoquímico para la proteína Spike viral, desde el punto de vista formal el diagnóstico de COVID-19 no puede sostenerse. Se desconoce la razón.

\section{CONCLUSIÓN}

Hacen falta más reportes de casos de pacientes con este tipo de erupción vesicular que se ha descrito como una erupción viral específica de COVID 19, la típica descripción es un rash vesicular monomorfo localizado o diseminado, medianamente pruriginoso.

Una característica importante es que la erupción sigue el curso de la enfermedad y termina al concluir la infección.
Su presentación puede ser parte de síndromes inflamatorios sistémicos

\section{REFERENCIAS}

1. Marzano AV, Genovese G, Fabbrocini G, Pigatto P, Monfrecola G, Piraccini BM et al. Varicella-like exanthem as a specific COVID-19associated skin manifestation: multicenter case series of 22 patients. J Am Acad Dermatol. 2020; 83 (1): 280-285.

2. Fernandez-Nieto D, Ortega-Quijano D, Jimenez-Cauhe J, BurgosBlasco P, de Perosanz-Lobo D, Suarez-Valle A et al. Clinical and histological characterization of vesicular COVID-19 rashes: a prospective study in a tertiary care hospital. Clin Exp Dermatol. 2020; 45 (7): 872-875. doi: 10.1111/ced.14277.

3. Mahé A, Birckel E, Merklen C, Lefebvre P, Hannedouche C, Jost $M$ et al. Histology of skin lesions establishes that the vesicular rash associated with COVID-19 is not "varicella-like". J Eur Acad Dermatol Venereol. 2020; 34 (10): e559-e561.

4. Lavery MJ, Bouvier CA, Thompson B. Cutaneous manifestations of COVID-19 in children (and adults): a virus that does not discriminate. Clin Dermatol 2020. 2020; 14: 40-44.

5. Sokolovsky S, Soni P, Hoffman T, Kahn P, Scheers-Masters J. COVID-19 associated Kawasaki-like multisystem inflammatory disease in an adult. Am J Emerg Med. 2021; 39: 253.e1-253.e2.

6. Labe P, Ly A, Sin C, Nasser M, Chapelon-Fromont E, Said PB et al. Erythema multiforme and Kawasaki disease associated with COVID-19 infection in children. J Eur Acad Dermatol Venereol. 2020; 34: e532-e652.

7. Dworakowska D, Grossman AB. Thyroid disease in the time of COVID-19. Endocrine. 2020; 68 (3): 471-474.

Conflicto de intereses: Los autores manifiestan que no existe conflicto de intereses. 